\title{
Expression of the inhibitor of DNA-binding (ID)- I protein as an angiogenic mediator in tumour advancement of uterine cervical
}

\section{cancers}

\author{
MK Maw', J Fujimoto*,I and T Tamaya' \\ 'Department of Obstetrics and Gynecology, Graduate School of Medicine, Gifu University School of Medicine, I-I Yanagido, Gifu City 50 I- I I94, Japan
}

\begin{abstract}
The ID protein, an inhibitor of basic helix-loop-helix $(\mathrm{HLH})$ transcription factors, has been involved in multiple cellular processes. To investigate the association between tumour advancement and ID expressions of uterine cervical cancers, the levels of ID- I, ID-2 and ID-3 mRNAs were determined by real-time reverse transcription-polymerase chain reaction and the histoscore with the localisation of ID- I was determined by immunohistochemistry and patient survival in 60 patients. ID-I histoscores and mRNA levels both significantly $(P<0.05)$ increased in uterine cervical cancers according to clinical stage regardless of histopathological type or lymph node metastasis. Furthermore, the 36 -month survival rate of the 30 patients with high ID-I was poor (60\%), whereas that of the other 30 patients with low ID-I was significantly higher (83\%). ID-I histoscores and mRNA levels significantly $(P<0.000$ I) correlated with microvessel counts in uterine cervical cancers. Tumour cells show mostly diffuse to strong cytoplasmic expression of ID-I and also very faint expression in endothelial cells. Moreover, ID-I expression not only correlated with microvessel counts but also correlated significantly with histoscore. Therefore, ID-I might work on tumour advancement through angiogenic activity and is considered to be a candidate for a prognostic indicator in uterine cervical cancers.
\end{abstract}

British Journal of Cancer (2008) 99, I557- 1563. doi:I0.I038/sj.bjc.6604722 www.bjcancer.com

Published online 28 October 2008

(c) 2008 Cancer Research UK

Keywords: ID-I; uterine cervical cancer; angiogenesis; prognostic indicator; tumour advancement

The family of inhibitors of DNA-binding (ID) proteins consists of four members of basic helix-loop-helix (bHLH) transcription factors lacking the DNA-binding domain (Norton et al, 1998a). Therefore, they act as dominant-negative regulators of bHLH proteins by forming transcriptionally inactive Id-bHLH protein complexes (Riechmann et al, 1994; Riechmann and Sablitzky, 1995). ID proteins play key roles in the regulation of cell differentiation during neurogenesis, lymphoiesis and angiogenesis. Their functions also include the promotion of cell growth and cell cycle progression, and apoptotic induction (Lyden et al, 1999; Norton, 2000).

Regarding tumour cell proliferation, ID-1 inhibited the promoter region of the tumour suppressor gene CDKN2A/p16, supporting the role of ID-1 as a potential oncogene (Alani et al, 2001). Furthermore, ID proteins also inhibited the transformationspecific sequence (ETS) transcription factors of an avian erythroblastosis virus, E26 (Yates et al, 1999), which are able to suppress p16 expression by binding to and activating its promoter. This indicates that IDs might inhibit the p16 promoter, and thereby increase tumour cell proliferation, through interactions with ETS transcription factors directly and indirectly (Ohtani et al, 2001). Both IDs and ETS transcription factors have previously been implicated in the regulation of angiogenesis (Lyden et al, 1999;

*Correspondence: Professor J Fujimoto; E-mail: jf@gifu-u.ac.jp Received 10 July 2008; revised 15 September 2008; accepted 16 September 2008; published online 28 October 2008
Wernert et al, 2003). The ID interactors-E protein transcription factors E12 (also known as epididymal sperm-binding protein, ELSPBP1), E47 (also known as E2A and TCF3), E2-2 (also known as TCF4) and HEB (also known as TCF12) (Yan et al, 1997), retinoblastoma protein (RB) (Lasorella et al, 2000) and ETS proteins (Ohtani et al, 2001) - are all implicated in tumorigenesis.

Recently, several reports have shown that ID-1 protein can induce cell proliferation and increase DNA synthesis, and that it can immortalise mammalian cells in corporation with other oncogenes (Norton and Atherton, 1998b; Alani et al, 1999). ID-1 overexpression has been found in several types of primary human cancers including breast, pancreatic, prostate, nasopharyngeal, melanoma and cervical cancers (Langlands et al, 2000; Lin et al, 2000; Polsky et al, 2001; Schindl et al, 2001, 2003; Wang et al, 2002; Ouyang et al, 2002a; Schoppmann et al, 2003; Lee et al, 2004; Straume and Akslen, 2005; Jang et al, 2006). IDs activate VEGF-dependent mobilisation of circulating endothelial cells and endothelial precursor cells from the bone marrow (Lyden et al, 2001). Further, ID-1 might act by transcriptional repression of thrombospondin (TSP)-1, a well-known angiogenesis inhibitor (Volpert et al, 2002). TSP-1 was more frequently expressed in leiomyoma compared with uterine smooth muscle tumour of uncertain malignant potential and leiomyosarcoma (Bodner-Adler et al, 2006).

Previous studies reported, expression of ID-1 was shown as an independent prognostic factor in cervical cancer with long-time follow-up, even more significant in early-stage disease. Over expression of ID-1 is associated with more aggressive behavior of 
tumour cells in cervical cancer (Schindl et al, 2001). However, no evidence clarifying the direct association between tumour advancement and ID protein expression is available in human primary cancer so far.

To elucidate the clinical implication of IDs in uterine cervical cancers, we analysed the manner expression of ID proteins in uterine cervical cancer progression according to clinical backgrounds, their influence on the survival of the patients and the association between ID mRNA expression and neoangiogenesis, assessed by assessment of microvessel density (MVD).

\section{MATERIALS AND METHODS}

\section{Patients and tissues}

Prior informed consent for the following studies was obtained from all patients and approval was given by the Research Committee for Human Subjects, Gifu University School of Medicine. Sixty patients ranging from 35 to 79 years of age with uterine cervical cancers (stage I, 21 cases; stage II, 21 cases; and stage III, 18 cases; squamous cell carcinoma (SCC), 42 cases and adenocarcinoma (AD), 18 cases) underwent surgery at the Department of Obstetrics and Gynecology, Gifu University School of Medicine, between September 1998 and August 2004. Patient prognosis was analysed in relation to a 36 -month survival rate. None of the patients had received any pre-operative therapy before the uterine cervical cancer tissue was taken in surgery. A part of each tissue of uterine cervical cancers was snap-frozen in liquid nitrogen and stored at $-80^{\circ} \mathrm{C}$ to determine ID-1, ID-2 and ID-3 mRNA levels and those for immunohistochemistry were fixed with $10 \%$ formalin and embedded in paraffin wax. The clinical stage of uterine cervical cancers was determined by International Federation of Obstetrics and Gynecology (FIGO) classification (International Federation of Obstetrics and Gynecology (FIGO) News, 1989).

\section{Immunohistochemistry}

Sections $(4 \mu \mathrm{m})$ of formalin-fixed paraffin-embedded tissue samples from uterine cervical cancers were cut with a microtome and dried overnight at $37^{\circ} \mathrm{C}$ on a silanised-slide (Dako, Carpinteria, CA, USA). The protocol of universal Dako-labelled Streptavidin - Biotin kit (Dako, Carpinteria, CA, USA) was followed for each sample. Samples were deparaffinised in xylene at room temperature for $30 \mathrm{~min}$, rehydrated with graded ethanol and washed in phosphate-buffered saline (PBS). The samples were then placed in $10 \mathrm{~mm}$ citrate buffer $(\mathrm{pH} 6.0)$ and boiled in a microwave for $10 \mathrm{~min}$ for epitope retrieval. Endogenous peroxidase activity was quenched by incubating tissue sections in $3 \% \mathrm{H}_{2} \mathrm{O}_{2}$ for $10 \mathrm{~min}$. The primary antibodies, rabbit anti-human ID-1 (SC-734, Santa Cruz Biotechnology Inc., Santa Cruz, CA, USA), mouse CD34 (Dako, Glostrup, Denmark) and rabbit anti-factor VIII-related antigen (Zymed, San Francisco, CA, USA) were used overnight at $4^{\circ} \mathrm{C}$ at dilutions of $1: 50,1: 40$ and $1: 2$, respectively. The slides were washed and biotinylated secondary antibody (Dako, Carpinteria, CA, USA) was applied for $30 \mathrm{~min}$ after rinsing in PBS, after which streptavidin-conjugated horseradish peroxidase (Dako, Carpinteria, CA, USA) was added for $30 \mathrm{~min}$. Slides were then washed and treated with the chromogen $3,3^{\prime}$-diaminobenzidine (Dako, Carpinteria, CA, USA) for $5 \mathrm{~min}$, then rinsed in PBS, and counterstained with Mayer's haematoxylin, dehydrated in graded ethanols, cleared in xylene and cover-slipped with a mounting medium, Entellan New (Merck, Darmstadt, Germany). For confirmation of the specificity for ID-1 antigen, we also used another ID-1 (SC-488) rabbit polyclonal antibody (Santa Cruz Biotechnology Inc., Santa Cruz, CA, USA) and we have observed the exact identified intensity and localisation of staining for ID-1 expression in tumour cells as ID-1 (SC-734) antibody. For the negative controls, the primary antibodies of ID-1, CD34 and factor VIII-related antigen were omitted and the corresponding preimmune animal serums (rabbit, mouse and rabbit, respectively) (Dako, Carpinteria, CA, USA) were used instead.

\section{Assessment of histochemical score (histoscore)}

All sections of immunohistochemical staining for ID-1 were evaluated in a semiquantitative fashion according to the method described by McCarty et al (1985), which considers both the intensity and the percentage of cells stained in each of five intensity categories. Intensities were classified as 0 (no staining), 1 (weak staining), 2 (distinct staining), 3 (strong staining) and 4 (very strong staining). For each stained section, a value-designated histoscore was obtained by application of the following algorithm: histoscore $=\sum(i+1) \times P i$, where $i$ and $P i$ represent intensity and percentage of cells that stain at each intensity, respectively, and corresponding histoscores were calculated separately. Results were assigned to four groups according to their overall scores: weak, $<160$; distinct, $161<$, $>220$; strong, $221<,>280$; very strong, $280<$. Immunohistochemistry results were analysed by two pathologists.

\section{Assessment of microvessel density}

The MVD was assessed with microvessel counts (MVCs) in sequential tissue sections stained with mouse CD34 and rabbit factor VIII-related antigen antibodies. Blood vessels with a clearly defined lumen or a well defined linear vessel shape, but not single endothelial cells, were taken into account for microvessel counting (Giatromanolaki et al, 2001). Fives areas of highest vascular density were chosen and microvessel counting was performed at $\times 200$ magnification by two investigators. The MVCs were determined as the mean of the vessel counts obtained from these fields (Maeda et al, 1996).

\section{Preparation of standard template for real-time reverse transcription - polymerase chain reaction (RT-PCR)}

Internal standard template for real-time PCR was produced by PCR amplification using the primers of ID-1 gene, 418-782 in the cDNA (ID-1-TS: $5^{\prime}$-TTGGAGCTGAACTCGGAA- $3^{\prime}$ and ID-1-TAS: $5^{\prime}$-TCTCTGGTGACTAGTAGGT-3' ${ }^{\prime}$ ); ID-2 gene, 907-1253 in the cDNA (ID-2-TS: $5^{\prime}$-CTAAGCAGACTTTGCCTTT- $3^{\prime}$ and ID-2-TAS: $5^{\prime}$-CTGAAATAAAGCAGGCAATC-3'); ID-3 gene, 686-1009 in the cDNA (ID-3-TS: 5'-GAACTTGTCATCTCCAACGA-3' and ID-3TAS: $5^{\prime}$-CACGCTCTGAAAAGACCT- $\left.{ }^{\prime}\right)$. The DNA template was purified using a GeneClean II kit (Qbiogene, Irvine, CA, USA). The copy numbers of the standard template were determined to quantitate ID-1, ID-2 and ID-3 mRNA level in samples for real-time RT-PCR.

\section{Real-time RT-PCR to amplify ID-1, ID-2 and ID-3 mRNAs}

Total RNA was extracted with the acid guanidinium thiocyanatephenol-chloroform method (Chomczynski and Sacchi, 1987). The total RNA ( $3 \mu \mathrm{g})$ was reverse transcribed using Moloney murine leukaemia virus reverse transcriptase (MMLV-RT, $200 \mathrm{U}^{-1} \mathrm{l}^{-1}$, Invitrogen, Carlsbad, CA, USA) and the following reagents: $250 \mathrm{~mm}$ Tris- $\mathrm{HCl}, \mathrm{pH} 8.3,375 \mathrm{~mm} \mathrm{KCl}, 15 \mathrm{~mm} \mathrm{MgCl}_{2}, 0.1 \mathrm{M}$ dithiothreitol, $10 \mathrm{~mm}$ deoxynucleotide (deoxyadenosine, deoxythymidine, deoxyguanosine and deoxycystidine) tri-phosphates (dNTPs) mixture and random hexamers (Invitrogen) at $37^{\circ} \mathrm{C}$ for $1 \mathrm{~h}$. The reaction mixture was heated for $5 \mathrm{~min}$ at $94^{\circ} \mathrm{C}$ to inactivate MMLV-RTase.

Real-time PCR was performed with a Takara Ex Taq R-PCR kit, Version 1.0 (Takara, Otsu, Japan), using a smart cycler system 
(Cepheid, Sunnyvale, CA, USA). The reaction solution $(25 \mu \mathrm{l})$ contained Takara Ex Taq HS $\left(5 \mathrm{U}^{-1}\right), 10 \times \mathrm{R}$-PCR Buffer $\left(\mathrm{Mg}^{2+}\right.$ free), $250 \mathrm{~mm} \mathrm{Mg}^{2+}$ solution, $10 \mathrm{~mm}$ dNTP mixture, SYBR Green I ( $1: 1000$ dilution; CambrexBio Science, Rockland Inc., Rockland, ME, USA) and $20 \mu \mathrm{M}$ of the primers of ID-1 gene, 545-675 in the cDNA (ID-1-S: $5^{\prime}$-ACGATCGCATCTTGTGTC-3' and ID-1-AS: $5^{\prime}$-CTTGTTCTCCCTCAGATCC-3' $)$; ID-2 gene, 907-1026 in the cDNA (ID-2-S: $5^{\prime}$-CTAAGCAGACTTTGCCTTT-3' and ID-2-AS: $5^{\prime}$-CATTCAGTAGGCTTGTGTC-3'); ID-3 gene, $709-873$ in the cDNA (ID-3-S: $5^{\prime}$-AAGGAGCTTTTGCCACTGA-3' and ID-3-AS: $5^{\prime}$-CCAGGAAGGGATTTGGTGAA- $3^{\prime}$ ) with the transcribed total RNA from the tissue and a serially diluted standard template. The real-time PCR reactions were initially denatured by heating at $95^{\circ} \mathrm{C}$ for $30 \mathrm{~s}$, followed by 40 cycles consisting of denaturation at $94^{\circ} \mathrm{C}$ for $10 \mathrm{~s}$, annealing at $55^{\circ} \mathrm{C}$ for $5 \mathrm{~s}$ and extension at $72^{\circ} \mathrm{C}$ for $20 \mathrm{~s}$. A strong linear relationship between the threshold cycle and the log concentration of the starting DNA copy number was always shown (correlation coefficient $>0.99$ ). Quantitative analysis was performed to determine the copy number of each sample.

\section{Statistical analysis}

Inhibitor of DNA-binding-1, ID-2 and ID-3 mRNA levels were determined from three parts taken from each tumour, and each sample was analysed in triplicate. ID-1 histoscores and mRNA levels were compared using Student's $t$-test. The 24-month survival rate was calculated according to the Kaplan-Meier method, and analysed with the log-rank test. The correlations between ID-1 histoscores and mRNA levels with MVCs were performed with bivariate Pearson's correlation. Differences were considered significant when $P$ was less than 0.05 .

\section{RESULTS}

Inhibitor of DNA-binding-1 mRNA levels significantly increased with increasing clinical stages $(\mathrm{I}<\mathrm{II}<\mathrm{III} ; P<0.05)$ of uterine cervical cancers, regardless of histopathological type and lymph node metastasis (Figure 1). However, there was no significant difference in ID-2 or ID-3 mRNA levels according to clinical stage, histopathological type or lymph node metastasis in uterine cervical cancers, as shown in Figure 1. These results prompted us to concentrate our investigation on ID-1 in uterine cervical cancers.

Inhibitor of DNA-binding-1 staining was diffusely located in the cancer cells. Although ID-1 expression in stroma cells was weak or negative, perivascular cells of intratumoral microvessels were strongly positive in all cases (Figure 2A, a representative case, 46-year-old patient, stage IIb, squamous cell carcinoma). Because ID-1 is not a transcription factor per se, it lacks the nuclear localisation signal found on many basic HLH proteins but gives a cytoplasmic signal instead (Maruyama et al, 1999; Lin et al, 2000; Schindl et al, 2001). ID-1 diffuse cytoplasmic staining was seen from moderate to strong intensity in most cases whereas nuclear staining was observed only occasionally (Figure 2B).

Inhibitor of DNA-binding-1 histoscore in cancer cells significantly $(P<0.001)$ correlated with corresponding mRNA levels in each tissue, as shown in Figure 3. Although there was no significant difference in ID-1 histoscores in cancer cells according to histopathological type and lymph node metastasis, ID-1 histoscores significantly $(\mathrm{I}<\mathrm{II}<\mathrm{III} ; P<0.05)$ increased with increased clinical stages of uterine cervical cancers (Figure 4), as did ID-1 mRNA.

Furthermore, the 60 patients who underwent surgery were arbitrarily divided into two equal groups based on ID-1 histoscores and mRNA levels, with the midpoint being a histoscore of 140 and mRNA of $1.6 \times 10^{6}$ copies $\mu \mathrm{g}^{-1}$ total RNA, respectively. The two groups, determined independently by the ID-1 histoscores and mRNA levels, consisted of exactly the same patients. The prognosis of the 30 patients with high ID-1 ( $>140$ histoscore and $>1.6 \times 10^{6}$ copies $\mu \mathrm{g}^{-1}$ total RNA) in uterine cervical cancers was poor $(60 \%)$, whereas the 36-month survival rate of the other 30 patients with low ID-1 $\left(<140\right.$ histoscore and $<1.6 \times 10^{6}$ copies $\mu \mathrm{g}^{-1}$ total RNA) was higher $(83 \%)$, as shown in Figure 5.

Inhibitor of DNA-binding-1 expression was very weak in endothelial cells although Factor VIII-related antigen and CD34

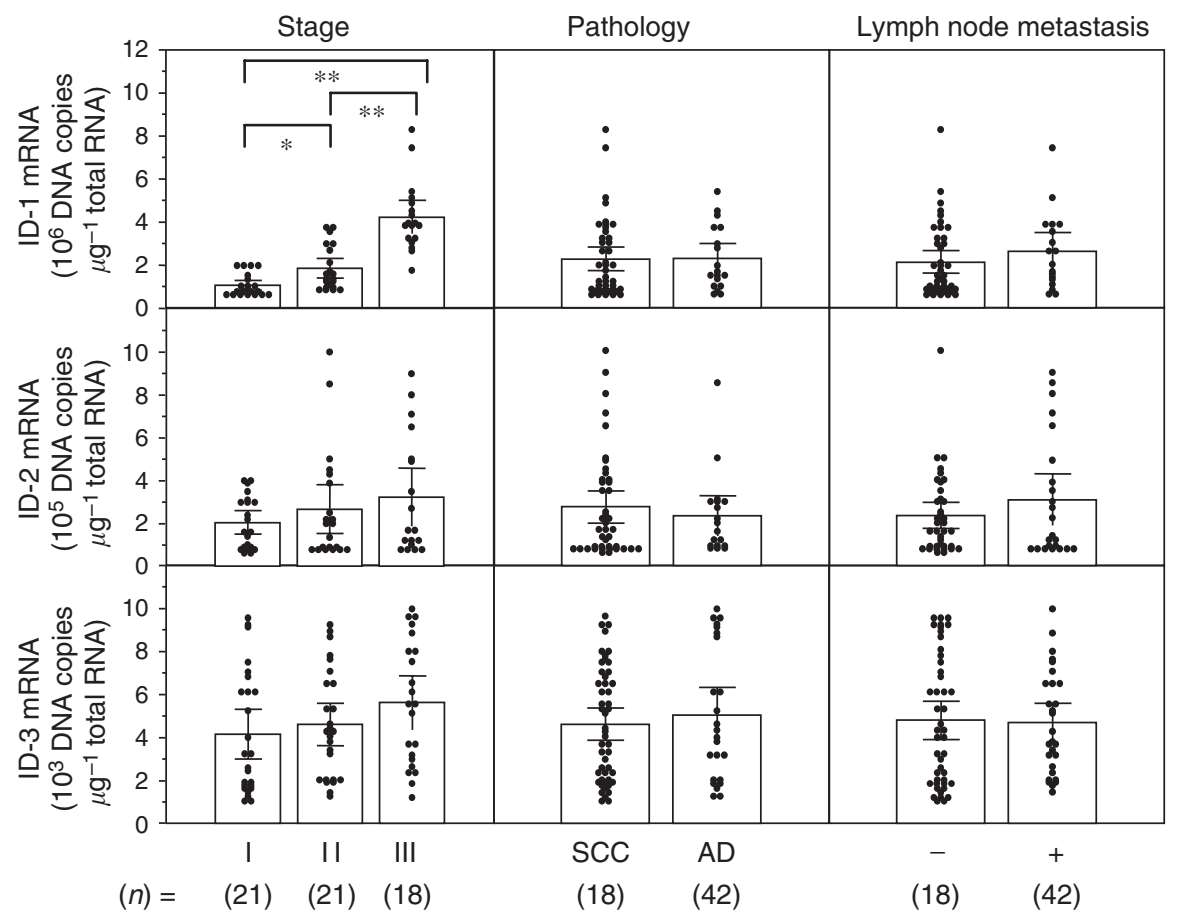

Figure I Inhibitor of DNA-binding-I, ID-2 and ID-3 mRNA levels in uterine cervical cancers classified according to clinical stage, histopathological type and lymph node metastasis. Clinical staging of uterine cervical cancers was done according to FIGO. Each level is the mean \pm s.d. of nine determinations. SCC, squamous cell carcinoma; AD, adenocarcinoma. $* P<0.05 ; * * P<0.001$ 


\section{ID-I expression in uterine cervical cancers}

A

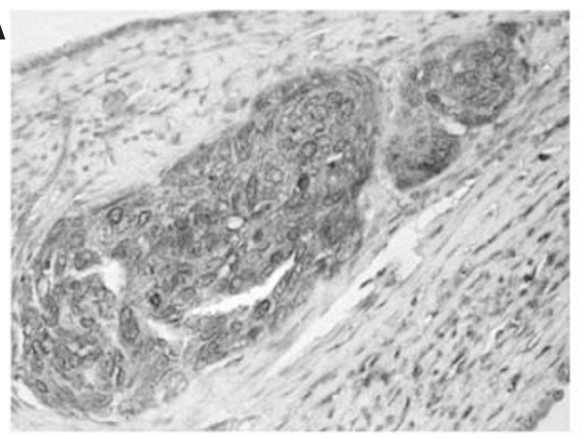

ID-1

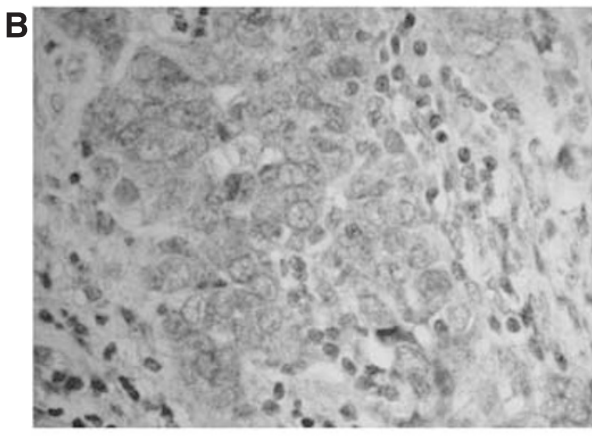

I

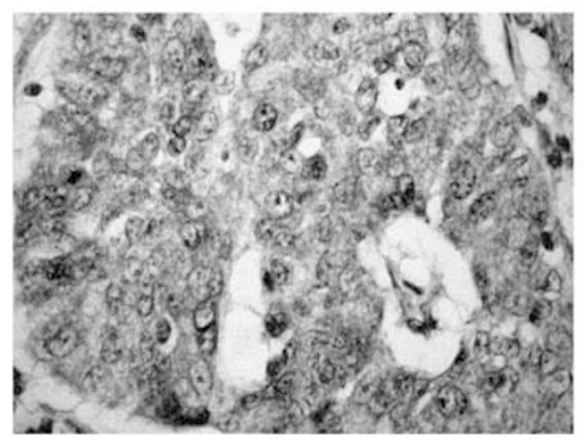

III

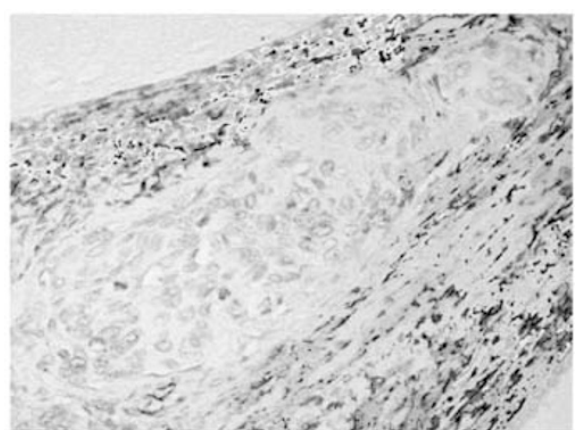

Negative control

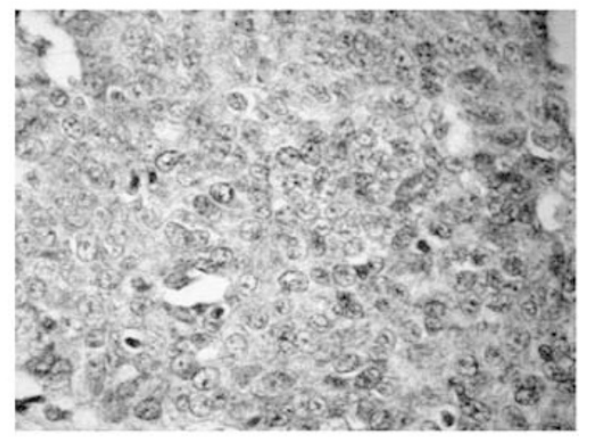

II

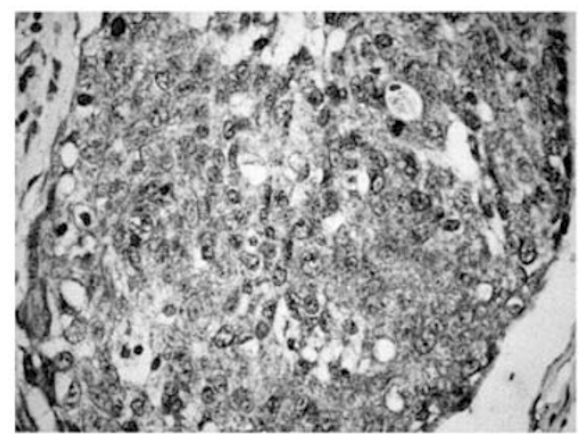

IV

Figure 2 (A). Immunohistochemical staining for positive and negative ID-I staining in squamous cell carcinoma of uterine cervical cancers. (B). Immunohistochemical staining for ID-I representing cases from each stage in uterine cervical cancers. Weak staining (score I I I) stage l; distinct (score 167) stage II; strong (score 264) stage III and very strong (score 392) stage IV, showing strong cytoplasmic expression in tumour cells. Overall scores: weak, $<$ 160; distinct, $|6|<,>220$; strong, 22|<, >280; very strong, $280<$. (original magnification $\times 400$ ). Rabbit anti-human ID-I (SC-734, Santa Cruz Biotechnology Inc., Santa Cruz, CA, USA) was used at a dilution of I:50 as the primary antibody (original magnification $\times 200$ ).

expression were strong. In tissue sections, weak ID-1 expression was associated with low MVD whereas strong ID-1 expression was associated with abundant microvessels. The ID-1 histoscores in cancer cells significantly correlated with MVC-CD34 (MVCs determined by immunohistochemistry for CD34; $\quad r=0.833$, $P<0.0001$ ) and MVC-F-VIII (MVCs determined by immunohistochemistry for factor VIII-related antigen; $r=0.742, P<0.0001)$; and ID-1 mRNA levels also correlated with MVC-CD34 $(r=0.892$, $P<0.0001)$ and MVC-F-VIII $(r=0.768, P<0.0001)$, as shown in Figure 6.

\section{DISCUSSION}

This study is, to our knowledge, the first to reveal that ID-1 expression in the cancer cells increased with tumour advancement of uterine cervical cancers. Also, the patients with high ID-1 expression had a lower survival rate compared with patients with low ID-1 expression. Negative prognostic impacts of increased ID-1 expression have been shown in breast cancers (Schoppmann et al, 2003), pancreatic cancers (Lee et al, 2004), melanoma (Straume and Akslen, 2005), cervical cancers (Schindl et al, 2001), and ovarian carcinomas (Schindl et al, 2003). This is in line with our finding. Therefore, ID-1 is recognised as a novel indicator of tumour advancement and patient prognosis in uterine cervical cancer.

Previously, no correlation between expression of ID proteins and angiogenesis, assessed by MVD was observed in cervical cancers (Schindl et al, 2001). But contrary to their finding, present study showed that mostly diffuse to strong cytoplasmic expression of ID-1 in tumour cells and also very weak ID-1 expression in endothelial cells. Moreover, ID-1 expression not only correlated with microvessel counts but also correlated significantly with histoscore. These data indicate that ID-1 overexpression is found to be closely related to tumour angiogenesis, a higher density of intratumoral vessel and poor survival in cervical cancer. Therefore, ID-1 is a candidate for angiogenic mediator as the clinical relevance of angiogenesis assessed by MVD. 


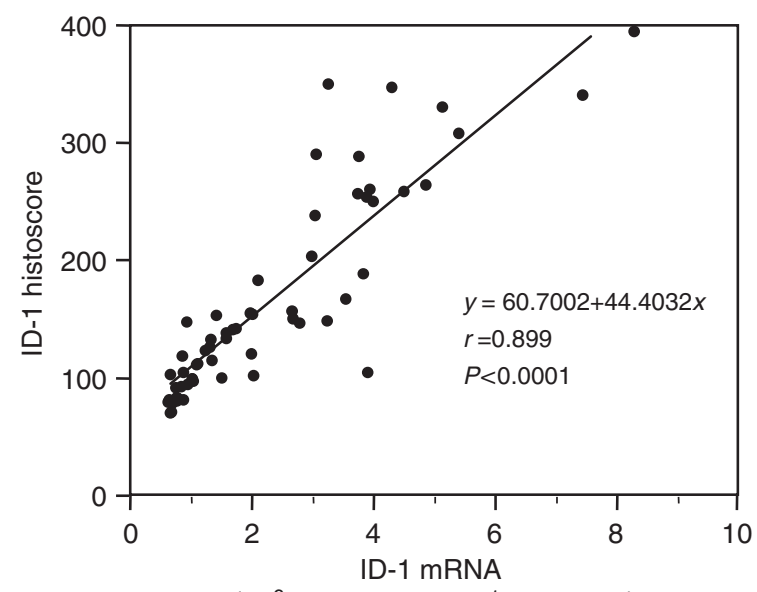

(10 $10^{6}$ DNA copies $\mu \mathrm{g}^{-1}$ total RNA)

Figure 3 Correlation between ID-I histoscores in cancer cells and mRNA ( $10^{6}$ DNA copies $\mu \mathrm{g}^{-1}$ total RNA) levels in uterine cervical cancers. ID-I histoscores and mRNA levels were determined by immunohistochemistry and real-time RT-PCR, respectively. Each level is the mean \pm s.d. of nine determinations.

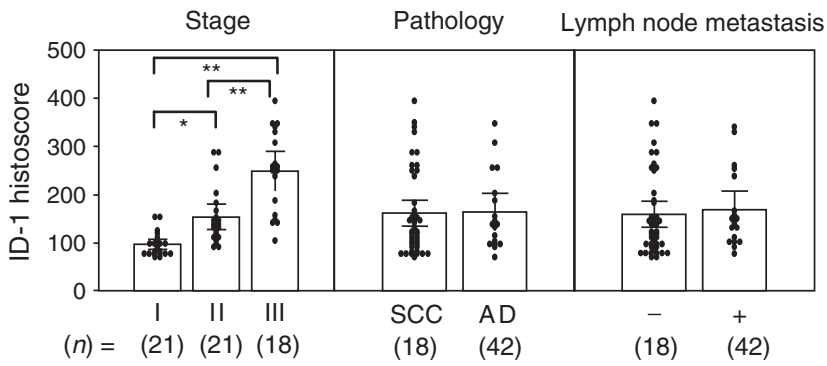

Figure 4 Inhibitor of DNA-binding-I histoscores in uterine cervical cancers classified according to clinical stage, histopathological type and lymph node metastasis. Clinical staging of uterine cervical cancers was done according to FIGO. Each level is the mean \pm s.d. of nine determinations. SCC, squamous cell carcinoma; $A D$, adenocarcinoma. $* P<0.05$; $* * P<0.00$ I

Angiogenesis is essential for development, growth and advancement of solid tumours (Folkman, 1985). The angiogenic factors vascular endothelial growth factor (VEGF) (Fujimoto et al, 1999a) and thymidine phosphorylase identified with platelet-derived endothelial cell growth factor (Fujimoto et al, 1999b, c, 2000) and interleukin (IL-8) along with the angiogenic transcriptional factor ETS-1 (Fujimoto et al, 2002) work on angiogenesis in uterine cancers.

Inhibitor of DNA-binding-1 is a regulator of basic HLHmediated transcription (Norton et al, 1998a) and causes cells to pass a mitogen-restricted point in late G1 phase (Le Jossic et al, 1994). Therefore, ID-1 has been suggested as responsible for some of the changes in gene expression that lead to increased growth and invasion of tumour cells (Lyden et al, 1999). Moreover, the ectopic expression of ID-1 increases the proliferation, migration, invasion and metastasis of breast cancer cells (Desprez et al, 1998; Lin et al, 2000). Although ID-1 has been shown to interact with various cell cycle regulators (Alani et al, 2001; Ohtani et al, 2001), ID-1 seems to be an essential factor in the promotion of G1/S cell cycle transition in certain cancers by inactivating of p16 and increasing of CDK4 activity/RB (Polsky et al, 2001; Ouyang et al, 2002b; Singh et al, 2002). However, additional studies are required to determine the mechanism of interaction between ID-1 and various cell cycle regulators.

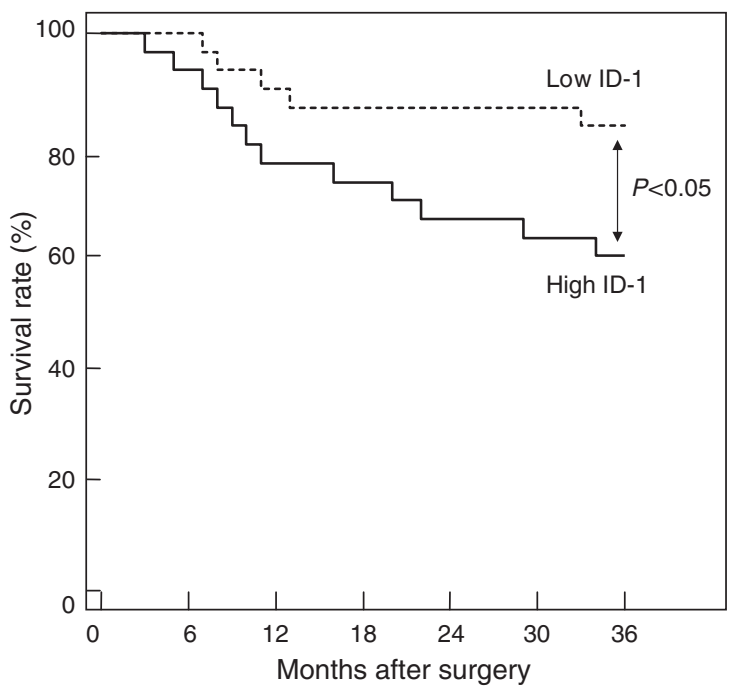

Figure 5 Survival rate after surgery for uterine cervical cancers. Patient prognosis was analysed with a 36-month survival rate. High ID-I, cases with high histoscores and mRNA levels ( $>140$ histoscore and $>1.6 \times 10^{6}$ copies $\mu \mathrm{g}^{-1}$ total RNA, respectively); $n=30$. Low ID-I, cases with low histoscores and mRNA levels $\left(<140\right.$ histoscore and $<1.6 \times 10^{6}$ copies $\mu \mathrm{g}^{-1}$ total RNA, respectively); $n=30$.

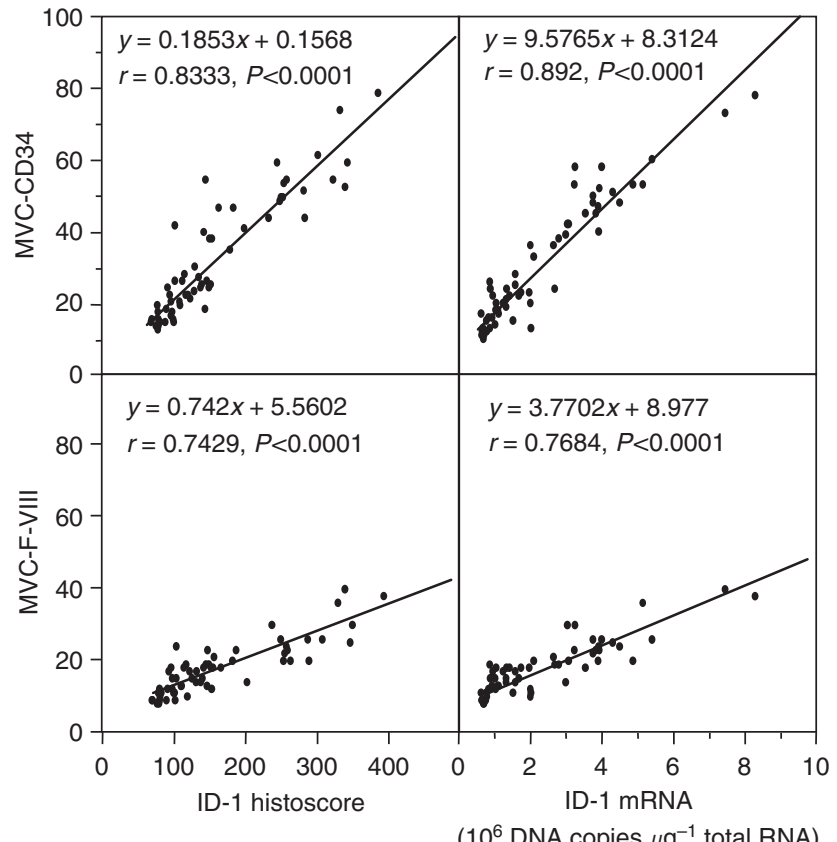

Figure 6 Correlation of ID-I histoscores in cancer cells and mRNA levels in uterine cervical cancers with microvessel counts (MVCs). Each level is the mean \pm s.d. of nine determinations.

Recently, TSP-1, an endogenous inhibitor of neovascularisation has been identified as a target of ID-1 that is negatively regulated by ID-1 in the regulation of angiogenesis (Volpert et al, 2002). Thrombospondin-1 suppresses angiogenesis by inhibiting endothelial cell proliferation and inducing endothelial cell apoptosis (Zhang et al, 2003). For example, in the ID-1 -/- mice, transcription of TSP-1 is increased, which is associated with inhibition of bFGF and VEGF-induced angiogenesis. This phenotype can be reversed by inactivation of TSP-1 function (Volpert et al, 2002). In addition, microvessel density count was negatively 
associated with the intensity of TSP-1 expression in uterine cervical cancer (Wu et al, 2004). An inverse relation between ID-1 and TSP-1 expression supports the significant role of ID-1 in the regulation of this complex multitarget protein (Straume and Akslen, 2005). These previous studies suggested that due to ID-1 suppression, TSP-1 expression might be lost with tumour advancement, resulting in drastic tumour angiogenesis that accelerates tumour advancement. These provide evidence that clarifies the association between ID-1 overexpression and tumour angiogenesis in human primary cancer.

Inhibitor of DNA-binding-1 expression was high in two androgen-independent prostate cancer cell lines, DU145 and PC3, but its expression is undetectable in the androgen-dependent cell line LNCaP under serum-free conditions (Ling et al, 2003). As prostate cancer progression and aggressiveness are judged by its response to androgen, these results support the role of ID-1 expression in tumour progression. Furthermore, ID-1 expression was higher in highly aggressive breast cancer cell lines such as MDA-MB321 and MDA-MB-435 compared with the less aggressive cell lines such as MCF7 and T47D. Ectopic ID-1 expression in T47D cells led to increased cell growth, invasion ability and reduced sensitivity to sex hormones (Lin et al, 2000). In addition, stable transfection of breast cancer cells with the antisense ID-1 vector also reduces lung metastasis after their inoculation into nude mice (Fong et al, 2003). These results support the role of ID-1 in metastasis of breast cancer and also suggest inactivation of ID-1 as a therapeutic strategy in the treatment of metastatic breast cancer. Therefore, ID-1 protein may be an important new target molecule for antiangiogenic drug design in cancer treatment. It is strongly suggested that transcriptional suppression of TSP-1 by ID-1 may play an important part in promoting angiogenesis in the uterine cervical cancers.

To conclude, this study suggests that ID-1 promotes tumour advancement of uterine cervical cancer through angiogenesis, leading to poor prognosis, and provides a novel therapeutic approach in uterine cervical cancers.

\section{ACKNOWLEDGEMENTS}

We thank Mr John Cole for proofreading the English of this paper.

\section{REFERENCES}

Alani RM, Hasskarl J, Grace M, Hernandez MC, Israel MA, Munger K (1999) Immortalization of primary human keratinocytes by the helix-loop-helix protein, Id-1. Proc Natl Acad USA 96: 9637-9641

Alani RM, Young AZ, Shifflett CB (2001) Id1 regulation of cellular senescence through transcriptional repression of p16/Ink2a. Proc Natl Acad Sci USA 98: 7812-7816

Bodner-Adler B, Nather A, Bodner K, Czerwenka K, Kimberger O, Leodolter S, Mayerhofer K (2006) Expression of Thrombospondin 1 (TSP-1) in patients with uterine smooth muscle tumors: An Immunohistochemical Study. Gynecol Oncol 103: 186-189

Chomczynski P, Sacchi N (1987) Single-step method of RNA isolation by acid guanidinium thiocyanate-phenol-chloroform extraction. Anal Biochem 162: $156-159$

Desprez PY, Lin CQ, Thomasset N, Sympson CJ, Bissell MJ, Campisi J (1998) A novel pathway for mammary epithelial cell invasion induced by the helix-loop-helix protein Id-1. Mol Cell Biol 18: 4577-4588

Folkman J (1985) Tumor angiogenesis. Adv Cancer Res 43: 175-203

Fong S, Itahana Y, Sumida T, Singh J, Coppe JP, Liu Y, Richards PC, Bennington JL, Lee NM, Debs RJ, Desprez PY (2003) Id-1 as a molecular target in therapy for breast cancer invasion and metastasis. Proc Natl Acad Sci USA 100: $13543-13548$

Fujimoto J, Aoki I, Toyoki H, Khatun S, Tamaya T (2002) Clinical implications of expression of ETS-1 related to angiogenesis in uterine cervical cancers. Ann Oncol 13: $1598-1604$

Fujimoto J, Sakaguchi H, Aoki I, Tamaya T (2000) The value of plateletderived endothelial cell growth factor as a novel predictor of advancement of uterine cervical cancers. Cancer Res 60: 3662-3665

Fujimoto J, Sakaguchi H, Hirose R, Ichigo S, Tamaya T (1999a) Expression of vascular endothelial growth factor (VEGF) and its mRNA in uterine cervical cancers. Br J Cancer 80: $827-833$

Fujimoto J, Sakaguchi H, Hirose R, Ichigo S, Tamaya T (1999b) The expression of platelet-derived endothelial cell growth factor (PD-ECGF) and its mRNA in uterine cervical cancers. Br J Cancer 79: 1249-1254

Fujimoto J, Sakaguchi H, Hirose R, Wen H, Tamaya T (1999c) Clinical implication of expression of platelet-derived endothelial cell growth factor (PD-ECGF) in metastatic lesions of uterine cervical cancers. Cancer Res 59: 3041 - 3044

Giatromanolaki A, Sivridis E, Brekken R, Thorpe PE, Anastasiadis P, Gatter KC, Harris AL, Koukourakis MI (2001) The angiogenic 'vascular endothelial growth factor/flk-1 (KDR) receptor' pathway in patients with endometrial carcinoma. Cancer 92: 2569-2577

International Federation of Obstetrics and Gynecology (FIGO) News (1989) FIGO News. Int J Gynecol Obstet 28: 189-193

Jang KS, Han HX, Paik SS, Brown PH, Kong G (2006) Id-1 overexpression in invasive ductal carcinoma cells is significantly associated with intratumoral microvessel density in ER-negative/node-positive breast cancer. Cancer Lett 244: 203-210

Langlands K, Down G.A, Kealey T (2000) Id proteins are dynamically expressed in normal epidermis and dysregulated in squamous cell carcinoma. Cancer Res 60: 5929-5933

Lasorella A, Noseda M, Beyna M, Yokota Y, Iavarone A (2000) Id2 is a retinoblastoma protein target and mediates signaling by Myc oncoproteins. Nature 407: 592-598

Le Jossic K, Ilyin GP, Loyer P, Glaise D, Cariou S, Guguen-Guillouzo C (1994) Expression of helix-loop-helix factor Id-1 is dependent on the hepatocyte proliferation and differentiation status in rat liver and in primary culture. Cancer Res 54: 6065-6068

Lee KT, Lee YW, Lee JK, Chio SH, Rhee JC, Paik SS, Kong G (2004) Overexpression of Id-1 is significantly associated with tumour angiogenesis in human pancreas cancer. Br J Cancer 90: 1198-1203

Lin CQ, Singh J, Murata K, Itahana Y, Parrinello S, Liang SH, Gillett CE, Campisi J, Desprez PY (2000) A role for Id-1 in the aggressive phenotype and steroid hormone response of human breast cancer cells. Cancer Res 60: $1332-1340$

Ling MT, Wang X, Ouyang XS, Xu K, Tsao SW, Wong YC (2003) Id-1 expression promotes cell survival through activation of NF-kappaB signaling pathway in prostate cancer cells. Oncogene 22: $4498-4508$

Lyden D, Hattori K, Dias S, Costa C, Blaikie P, Butros L, Chadburn A, Heissig B, Marks W, Witte L, Wu Y, Hicklin D, Zhu Z, Hackett NR, Crystal RG, Moore MA, Hajjar KA, Manova K, Benezra R, Rafii S (2001) Impaired recruitment of bone-marrow-derived endothelial and hematopoietic precursor cells blocks tumor angiogenesis and growth. Nat Med 7: $1194-1201$

Lyden D, Young AZ, Zagzag D, Yan W, Gerald W, O’Reilly R, Bader BL, Hynes RO, Zhuang Y, Manova K, Benezra R (1999) Id1 and Id3 are required for neurogenesis, angiogenesis and vascularization of tumour xenografts. Nature 401: 670-677

Maeda K, Chung YS, Ogawa Y, Takatsuka S, Kang SM, Ogawa M, Sawada T, Onoda N, Kato Y, Sowa M (1996) Thymidine phosphorylase/plateletderived endothelial cell growth factor expression associated with hepatic metastasis in gastric carcinoma. Br J Cancer 73: 884-888

Maruyama H, Kleeff J, Wildi S, Friess H, Buchler MW, Israel MA, Korc M (1999) Id-1 and Id-2 are overexpressed in pancreatic cancer and in dysplastic lesions in chronic pancreatitis. Am J Pathol 155: 815-822

McCarty Jr KS, Miller LS, Cox EB, Konrath J, McCarty Sr KS (1985) Estrogen receptor analyses. Correlation of biochemical and immunohistochemical methods using monoclonal antireceptor antibodies. Arch Pathol Lab Med 109: 716-721

Norton JD (2000) ID helix-loop-helix proteins in cell growth, differentiation and tumorigenesis. J Cell Sci 113: $3897-3905$ 
Norton JD, Atherton GT (1998b) Coupling of cell growth control and apoptosis functions of Id proteins. Mol Cell Biol 18: $2371-2381$

Norton JD, Deed RW, Craggs G, Sablitzky F (1998a) Id helix-loop-helix proteins in cell growth and differentiation. Trends Cell Biol 8: 58-65

Ohtani N, Zebedee Z, Huot TJ, Stinson JA, Sugimoto M, Ohashi Y, Sharrocks AD, Peters G, Hara E (2001) Opposing effects of Ets and Id proteins on p16INK4a expression during cellular senescence. Nature 409: $1067-1070$

Ouyang XS, Wang X, Lee DT, Tsao SW, Wong YC (2002a) Over expression of ID-1 in prostate cancer. J Urol 167: 2598-2602

Ouyang XS, Wang X, Ling MT, Wong HL, Tsao SW, Wong YC (2002b) Id-1 stimulates serum independent prostate cancer cell proliferation through inactivation of p16(INK4a)/pRB pathway. Carcinogenesis 23: $721-725$

Polsky D, Young AZ, Busam KJ, Anani RM (2001) The transcriptional repressor of p16/Ink4a, Id1, is up-regulated in early melanomas. Cancer Res 61: 6008-6011

Riechmann V, Sablitzky F (1995) Mutually exclusive expression of two dominant-negative helix-loop-helix (dnHLH) genes, Id4 and Id3, in the developing brain of the mouse suggests distinct regulatory roles of these dnHLH proteins during cellular proliferation and differentiation of the nervous system. Cell Growth Differ 6: $837-843$

Riechmann V, van Cruchten I, Sablitzky F (1994) The expression pattern of Id4, a novel dominant negative helix-loop-helix protein, is distinct from Id1, Id2 and Id3. Nucleic Acids Res 22: $749-755$

Schindl M, Oberhuber G, Obermair A, Schoppmann SF, Karner B, Birner P (2001) Overexpression of Id-1 protein is a marker for unfavorable prognosis in early-stage cervical cancer. Cancer Res 61: 5703-5706

Schindl M, Schoppmann SF, Strobel T, Heinzl H, Leisser C, Horvat R, Birner P (2003) Level of Id-1 protein expression correlates with poor differentiation, enhanced malignant potential, and more aggressive clinical behavior of epithelial ovarian tumours. Clin Cancer Res 9: 779-785

Schoppmann SF, Schindl M, Bayer G, Aumayr K, Dienes J, Horvat R, Rudas M, Gnant M, Jakesz R, Birner P (2003) Overexpression of Id-1 is associated with poor clinical outcome in node negative breast cancer. Int J Cancer 104: $677-682$

Singh J, Murata K, Itahana Y, Desprez PY (2002) Constitutive expression of the Id-1 promoter in human metastatic breast cancer cells is linked with the loss of NF-1/Rb/HDAC-1 transcription repressor complex. Oncogene 21: $1812-1822$

Straume O, Akslen LA (2005) Strong expression of ID-1 protein is associated with decreased survival, increased expression of ephrin-A1/ EPHA2, and reduced thrombospondin-1 in malignant melanoma. Br I Cancer 93: 933 - 938

Volpert OV, Pili R, Sikder HA, Nelius T, Zaichuk T, Morris C, Shiflett CB, Devlin MK, Conant K, Alani RM (2002) Id1 regulates angiogenesis through transcriptional repression of thrombospondin-1. Cancer Cell 2: $473-483$

Wang X, Xu K, Ling MT, Wong YC, Feng HC, Nicholls J, Tsao SW (2002) Evidence of increased Id-1 expression and its role in cell proliferation in nasopharyngeal carcinoma cells. Mol Carcinogen 35: $42-49$

Wernert N, Okuducu AF, Pepper MS (2003) Ets-1 is expressed in capillary blood vessels but not in lymphatics. J Pathol 200: $561-567$

Wu MP, Tzeng CC, Wu LW, Huang KF, Chou CY (2004) Thrombospondin 1 acts as a fence to inhibit angiogenesis that occurs during cervical carcinogenesis. J Cancer 10(1): $27-32$

Yan W, Young AZ, Soares VC, Kelley R, Benezra R, Zhuang Y (1997) High incidence of T-cell tumors in E2A-null mice and E2A/Id1 doubleknockout mice. Mol Cell Biol 17: 7317-7327

Yates PR, Atherton GT, Deed RW, Norton JD, Sharrocks AD (1999) Id helix-loop-helix proteins inhibit nucleoprotein complex formation by the TCF ETS-domain transcription factors. EMBO J 18: $968-976$

Zhang YW, Su Y, Volpert OV, Vande Woude GF (2003) Hepatocyte growth factor/scatter factor mediates angiogenesis through positive VEGF and negative thrombospondin 1 regulation. Proc Natl Acad Sci USA 100(22): $12718-12723$ 